\title{
The Role of Support Group for Parents of Children with Special Needs
}

\author{
Ujianti, P.R ${ }^{1}$ \\ ${ }^{1}$ Universitas Pendidikan Ganesha, Singaraja, Indonesia
}

\section{A R T I C LE IN F O}

Article history:

Available online on

February, 20 2018

Keywords:

Parents,

Children with special

needs,

Support group

\begin{abstract}
A B S T R A C T
To have children with special needs is a challenge for parents. Acceptance on the children condition is the main key in determining attitudes and taking steps needed for optimizing the children's growth and development. Unfortunately, many parents experience obstructions in accepting the condition of their children. This results in conflict within the parents themselves, with their spouses, or with other members of the family. This acceptance process itself has to go through several stages, namely denial, bargaining, anger, depression and acceptance. Many parents live in denial and anger before they can accept their children's condition. Parents' knowledge and understanding about their children's special needs is one of the supporting factors which lead to acceptance. Yet the fact is, many parents especially from the middle and lower classes lack of information and believe more in superstitions in society. This fact surely hinders the steps needed to accept their children's special condition and take proper care of them. The presence of support group which consist of parents of children with special needs and those concerned in the development of special needs children is a place for comfort, emotional release and information exchange for the parents.
\end{abstract}




\section{Introduction}

The birth of a child with a disability can affect the family in profound ways. Bernal (2006) observed that parents feel deep sadness, frustration and excruciating pain, which occur simultaneously with the experience of giving birth and raising children with special needs. The rejection showed by parents toward the presence of their child will affect their further growth and development. Studies have shown that early intervention will provide opportunity for optimum growth and development in children with special needs. Therefore, if parents of children with special needs still show non-acceptance of their existence, the steps toward intervention will be unlikely to take place. The research conducted by Xu \& Filler (2008) and Stalker, Brunner, Maguire and Mitchell (2011) found that in addition to teachers, parents' collaboration is one of the determining factors in child education. Having said this, parental involvement will be unlikely to obtain if parents are still in denial and refuse to accept their children's special condition.

Parents have been found to react differently when they discovered their child's special needs. Seligman and Darling (1989) mentioned that the psychological and social economic factors had an influence on reactions displayed by parents. The emotional states parents are under vary, from shock, denial, distress or anger, guilt, as well as fear and anxiety, before they finally come to accept and adapt to the reality (Dukes and Smith, 2007). In particular, mothers are the figures who are exceptionally vulnerable to adaptation issues due to their direct role in child birth.

Having a child with disability, a child whose dependency on the mother goes beyond what is normally expected, forces the mother to extend her affective links indefinitely (Kingston, 2007). It is only when parents reach the acceptance level that they can take the necessary steps for their child's growth and development.

\subsection{Theoretical Background}

\subsubsection{The Stages of Adjustment}

The state theory approach states that parents undergo a few stages after learning about their child's special needs. Several of these stages are similar to the stages of mourning and grief experienced by families over the death of their loved ones. The mentioned phases are shock and disturbance, denial, sadness, anxiety and fear, anger and finally acceptance. The stages of parental reaction adapted from Kubler-Rose (Seligman, 1989 and Dukes and Smith, 2007) are as follows:

1. Denial phase:

parents experience shock and disbelief. Denial occurs subconsciously to rationalize overwhelming emotions (Mangunsong, 2011). Parents are in denial to protect them from the pain that the mind or heart can't handle (Morrel and Palmer, 2006). They are in fear of what might happen to their child, confused as to how they are supposed to react in this situation, and visualize negative images of their child's future. At this stage parents begin to develop over protective attitudes and behavior to their child, family and themselves.

2. Bargaining:

At this phase, parents try to bargain or negotiate a compromise. Their reasoning is that if they put enough effort, then their child will somehow get better. Any improvement the child experiences will 3. Anger: be considered a compensation of the parents' hard attempt.

When parents realize that there is no significant improvement in their child, they may express anger. Parents start to blame themselves, God and their spouse for their child's condition. Their anger may be directed at the lack of help from the society or professionals, even to the point of feeling isolated. The continuous questioning from others and the staring from people who have no understanding of special needs children may trigger more anger in parents and become harmful if taken out on their child. Thus, at this phase children are in a vulnerable position. Parents' over protective attitude toward their child may also increase if the society's reaction tends to be negative.

4. Depression:

This occurs when parents have come to realize that their anger is unable to change their child's condition, and eventually reluctantly accept the situation which causes depression. In depression, they only see hopelessness, with no end in sight. 


\section{Acceptance:}

At this stage parents are able to discuss their child's condition more readily. They manage to balance love and intention to encourage independence. Their only concern for wanting their child to acquire certain social skills is their child's independence and not part of their ego as parents (that they have tried hard enough as shown at the bargaining phase). As presently they have the ability to discuss their child's condition openly, parents at this phase voluntarily collaborate with professionals to set a realistic plan for their child.

Quite similar to the stages above, according to Healey (1996) the first point of providing support for parents should be during a period of uncertain diagnosis, which can engender confusion or bewilderment. Following the rendering of a specific diagnosis, such as autism or a less definitive determination like pervasive developmental disorder, the parents' typical stages of adjustment are as follows:

1. Stage one

The parent may be shocked, and he or she may cry or become dejected. Sometimes parents may express their feelings through physical outbursts or, occasionally, inappropriate laughter.

\section{Stage two}

This is an extension of stage one, and some parents may deny their child's disability or try to avoid that reality in some other way. Some parents will search for or try to propose various actions in an attempt to change the reality. Some may "shop for a cure" or try to bargain for a different reality.

\section{Stage three}

At this stage, parents may feel anger. They may demonstrate their anger outwardly, in the form of rage, or become withdrawn and passive from intense feelings of guilt. Verbally attacking anyone who might be blamed for their unfortunate circumstance, including displacement of responsibility onto the original diagnostician or any supportive professionals, is common. If the parents are feeling angry, guilty, or both, professionals must understand this stage is a very positive point to reach in the process of adjustment and not become defensive if attacked.

4. Stage four

Parents become resigned to the fact that their child has a disability. In some situations, one or more of the family may slip into depression. Feelings of shame, guilt, hopelessness, and anxiety stemming from a new overwhelming burden of responsibility can become intense. For a few parents, retreating, accompanied by an attempt to hide the child, especially from friends and persons during organized or routine social encounters may be the first sign that they have begun to accept the fact their child has a disability. However, any inclination toward or demonstration of behavior that results in abnormal isolation of one or any family members must be prevented or eliminated.

5. Stage five

This is the stage of acceptance, meaning the parents have achieved an unconditional positive regard for the child. Specialists debate whether or not this stage of adjustment includes parents who show only acceptance of their child's condition, commonly called neutrality, or a very important new stage of cognition when parents not only begin to understand and appreciate their child but strengthen their skills in coping with life's trials as well as being able to help their child, themselves, and others. Reaching this stage is highly correlated with the school inviting parents to become team members in a program with caring professionals, and often paraprofessionals, that is designed to meet all of the child's needs.

6. Stage six

Parents are able to put their lives back together and enjoy living, imagine a future, and talk of their child free of undue emotion. They can discuss and participate in designing or providing instruction objectively.

\subsubsection{The Role of Support Group in Parental Acceptance}

Stalker, Brunner, Maguire, and Mitchell (2006) mentioned that the key element in overcoming obstacles occurring in the process of acceptance that parents go through is adequate, consistent and informal communication with parents. Parents need information about their children's special needs from teachers as well as child development professionals, yet prefer direct communication (face to face) or over the phone instead of written information which sometimes can be difficult to understand.

Winter (2006) explained that building a network of parents of special needs children who have similar challenges can help parents to accept their children's conditions. This support group can serve as a forum for parents to exchange information about activities, professionals and education programs which 
can be helpful for their children in addition to sharing their experiences of raising their children. It is of utmost importance though that support group encourages affirmative interactions; therefore, parents can experience positive emotions when being in it instead of anger and self-pity having shared the same struggles (Kingston, 2007). The participants of this support group other than parents of special needs children are experts, relevant professionals, and anyone who are concerned with special needs education regardless of whether they have family members with special needs.

During a meeting session in support group, parents can learn about how other parents deal with the challenges and obstacles they face (Winter, 2006). Parents of newly diagnosed children, who are in the middle of that overwhelming time of adjustment need to hear from other more experienced parents that it will get better (Morrell and Palmer, 2006). Hearing other parents share their experiences does not necessarily mean the reality they face is going to change, yet at least parents may feel better for positive attitudes can make a difference when facing the demands of raising children with special needs. Dealing with the really difficult times gets easier not necessarily because the situations are easier, but because with time parents become stronger.

Moreover, listening to other parents sharing their stories will help grow the understanding and awareness inside the other parents of special needs children that they are not alone in this situation as they thought they were at the bargaining phase. They need the support and help of other people if they would like their children to obtain adequate services and education.

\section{Methods}

Eight mothers of children with special needs, age range five to eight years old, were participating in focus group discussion. Four of the mothers were staying at home mothers and the other four were working at various sectors. They came from different religious and educational background, and have more than one children.

Three of eight participants in focus group discussion agreed to be interviewed to gain more data and understanding. The process of discussion as well the interviewed were recorded and transcribed.

\section{Findings and Discussion}

In the beginning, parents hope that one day their children will turn out normal. They see the speciality of their children as some kind of disease that needs to be cured. For parents who are still unable to accept their child's condition, they will send their child to a special school or even to an inclusive one. They also registered the children to join therapy in the hope that their child will 'gradually grow normal'.

... I hope that he could be like his older sibling who developed fast in literacy and was an achiever at school. He was already a very good reader when he was just in first grade...

(mother of Dion, 8 years old)

...Actually, his kindergarten teacher warned me that my son was 'special'. He would fit more in a special school. I enrolled him in this (special) school, but I hope he could have a place at a main stream school once he is in third grade...

(mother of Rafi, 7 years old)

Raising a child with special needs together with their siblings presents its own challenges for the family. It is quite common for parents who are still in denial to compare their special child to their other children and 'demand' that their child have the same ability as that of their normal siblings'. In several cases, spouses put the blame on each other as the cause of their child's disability or refuse any involvement in their child's growth and development process. If a couple is unable to go through this phase, then their marriage may be susceptible to divorce.

A mother recalled her experience when she was informed the first time about her daughter.

....After my meeting with her preschool teacher, I studied Erika and tried to remember anything she might have done that was different, that was not within the norm. She had always been a perfect baby. She rarely cried. She slept well. She ate well. Erika had reached all the developmental milestones on time. She was even doing some things ahead of schedule, such as knowing her ABCs by the age of one and half. How could anything be wrong with a child who could be so bright and so adorable? Look at her. She's talking. She can't be autistic... 
She is difficult to believe let alone accept what her daughter's teacher had said. In shock and disbelief stage, she subconsciously rationalize overwhelming emotions to protect herself from the pain that the mind or heart can't handle (Morrel and Palmer, 2006). She is in fear of what might happen to her daughter, confused as to how she is supposed to react in this situation. Many times she visualize negative images of her daughter's future.

In a number of cases parents have been found unable to accept their child's diagnosis. They would then connect their child's special needs with superstitions or mystics. A mother whose daughter was diagnosed with ADHD insisted that she was fine. When her daughter displayed impulsive behavior that put herself in danger, he called it part of the mystical ability that she possessed.

...since she was born, my daughter has had this 'special' ability. She can see and
hear sounds which most people cannot. That is why she is behaving this way ..."

( mother of Ratih , aged 7)

It is parents' superstitious and mystical beliefs used as an explanation for their child's condition that often obstruct necessary intervention measures. When parents found out there is nothing can be done about the situation, they started to bargain or negotiate a compromise. Their reasoning is that if they put enough effort, then their child will somehow get better. Any improvement the child experiences will be considered a compensation of the parents' hard attempt.

...Even after we were given a "real" diagnosis of Down Syndrome, my quest for the cure didn't let up. I read everything I could find about Down Syndrome, the various medications, and the current research. I believed that if I knew enough, I could somehow fix the situation. I equated my frenetic activity with hope and caring. If I tried hard enough, all would be well...

(mother of Lisa, 5 years old)

During this stage, parents will join any activities that can give them benefits. In addition, they will turn to spirituality and hope for a miracle. This is the period where parents try to find any sort of answer or explanation of their child's condition. All the efforts brought parents to the stage of anger and depression. They feel they have done everything they could but nothing is really change.

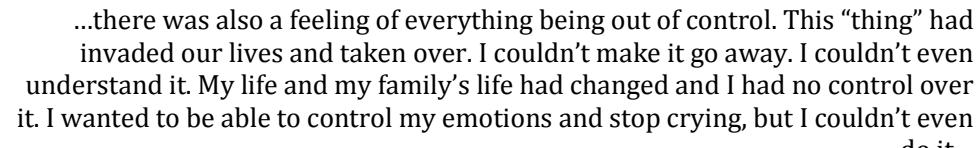

do it...

(Mother of Erika, 6 years old)

This hopelessness may result in parents' unwillingness and inability to think of and take the required steps for they feel that there is no point in doing anything. Further, they also experience loss of self-esteem and confidence in their ability as parents.

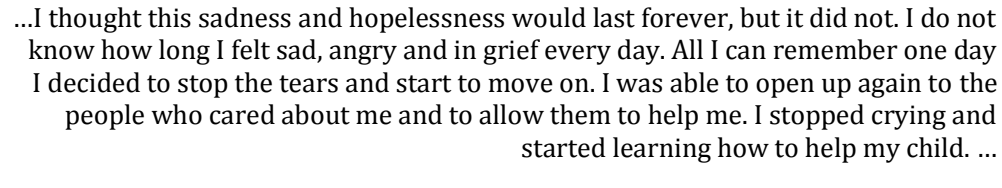

(mother of Erika, 6 years old)

When they have reached the acceptance phase, parents are able to get a wider perspective on life; one example is by pursuing personal interests which do not concern their child. This stage includes parental ability to discipline without feeling guilty because they can balance love and discipline to their children. It is also for the child's sake that parents can disregard their over protective behavior in realization that they will not be there for their child forever; therefore, they need to be prepared for independence. Further, parental acceptance presents itself in their ability to identify their child's positive qualities.

...my daughter was born and grew up normal. But, when she turned four she had a high fever and suddenly passed out before being in a coma. When she regained consciousness she lost all her abilities. It was like she turned into a baby again. Even now she is still practicing her speech. I went into shock and disbelief, 
especially when I learned that she might never be like other normal children again. However, over time I became grateful. It was fortunate that she only lost her abilities, not her life. Everytime I look into my daughter's face I am reminded that we can die anytime...

(mother of Sheila, aged 6)

Every parent goes through the above stages differently. Some parents may experience only a few or all the phases at one point. One of the common reactions reported is guilt. Winter (2006) even observed that for some parents grieving can turn into an unending episode since they have to deal with the delay in their child's development on an ongoing basis. Nevertheless, it is of importance to admit that they are still in grief in avoidance of continuous emotional tension and depression. Discussing their child's condition openly can help parents to move out of the denial phase (Winter, 2006).

If parents are unable to come out of the stage of denial and anger, they are unlikely to accept their child as part of the family. That is why some children with special needs are looked after by other members of the family such as their grandmother, uncle or aunt because their parents do not feel capable or embarrassed to raise children who are considered 'abnormal'. Some children live with their nucleus family, but are not schooled or given adequate stimulation because it is considered unworthy of doing; the children will not understand anything let alone improve.

Sullivan (in Whiteman and Yager, 2007) noted that as parents pass through the early stages of grief and shock, most begin to accept their child's situation and adjust to it. He also notes, however, that this initial level of acceptance is of acceptance is often relatively fragile and can be fraught with its own challenge.

Meeting and sharing with other parents of special needs children can become a catharsis or emotional release, particularly if there are volunteer professionals involved such as psychologists. These professionals can assist with the process of emotional release in a constructive way so not to make parents feel trapped in the negative and destructive nurturing role (Winter, 2006). The parents in support group can learn to recognize and acknowledge their mixed emotions or feelings since according to Whiteman and Yoger's (2007) research, parents who are least accepting of their range of feelings often seem to struggle more with their overall adjustment.

Support group can also function as a forum for information exchange about activities that their children can join.

...I received information from another mother in this group about a drawing teacher who took on students with special needs. Then, I asked a few other mothers who were interested to invite this teacher to our house and share the fees. Not long after that, we started to organize swimming sessions for our children, so now they have a variety of positive activities and exercise their motor skills at the same time. If a mum is unavailable, we will take turns looking after her child...

(a mother and member of a support group of mothers of special needs children )

Further, it is capable of accomplishing greater things, e.g., raising public's and other parents' awareness of special needs education.

...we proposed to school committee to hold a seminar about children with special needs by inviting speakers with related expertise in this area such as doctors, psychologists and practitioners. We also proposed that the school invite the general public and all parents regardless of their children's conditions. It was an event where we as parents of special needs children could empathize with one another, as well as have an open dialog and discussion with the society about our feelings and what our children were facing. We were also sending an indirect message out there in order that people could have a better acceptance of our children's condition. The overall response was positive since the information was presented by the experts. The distance that separated our world and that of parents of normal children felt somewhat closer...

(mother of Amel, aged 6, goes to inclusive school)

\section{Conclusion}

Parents of children with special needs undergo a number of phases and emotional sates, such as guilt, anger and denial before they can finally reach the acceptance stage. Parental acceptance plays an important role in the intervention process to help the child. One of the hindrances for parents to reach the level of acceptance is insufficient knowledge and understanding of their child's condition.

Support group serves as a forum where parents can exchange information about services and education for children with special needs, share their experience of raising children with special needs 
and a place for emotional release. Support group provides encouragement and assistance for parents in playing their roles given that the nature of interaction among members is affirmative and positive.

\section{References}

Auerbach, S. (2007). From Moral Supporters to Struggling Advocates: Reconceptualizing Parent Roles in Education Through the Experience ofWorking-Class Families of Color. Urban Education. 42 (3). 250-283

Bernal, C. (2006). Challenging the 'tragedy' Meeting the Needs of Children with Disabilities Families and Professional facing the Challenge Together. In H.K. Warner (Ed). Meeting The Needs of Special Children. London: Routledge.

Dukes, C., Smith, M. (2007). Working with Parents of Children with Special Education Needs. London: Sage Publication

Healey, W. (1996). Helping Parents Deal with the Fact Their Child has a Disability. Council for Exceptional Children. 3(5). Online at www.Idonline.org/articles/5937

Keown, L. (2010). Fathering and Mothering of Preschool Boys with Hyperactivity. International Journal of Behavioral Development. 35(2), 161-168

Kingston, A.K. (2007). Mothering Special Needs A Different Maternal Journey. Philadelphia: Jessica Kingsley Publisher.

Mangunsong, F. (2011). Psikologi dan Pendidikan Anak Berkebutuhan Khusus Jilid Kedua (Psycholoyi and Special Need Education 2nd Volume) . Jakarta: LPSP3 Universitas Indonesia

Morrell, M.F., Palmer, A. (2006). Parenting Across the Autism Spectrum Unexpected Lesson We Have Learned. Philadelphia: Jessica Kingsley Publisher.

Seligman, M., Darling, R.B. (1989). Ordinary Families, Special Children: A System Approach to Childhood Disability, New York: Guilford Press.

Stalker, K.O., Brunner, R., Maguire, R., Mitchell, J. (2011). Tackling the Barriers to Disabled Parents' Involvement in Their Children's Education. Educational Review. 63( 2). 233-250

Warner, H. K. (2006). Making Contact-Building Relationship. In H.K. Warner (Ed). Meeting The Needs of Special Children. London: Routledge.

Winter, J. (2006). Breakthrough Parenting For Children With Special Needs Raising The Bar of Expectations. San Fransisco: A Wiley Imprint

Whiteman, N.J., Yager, L.R. (2007). Building a Joyful Life with Your Child Who Has Special Needs. Philadelphia: Jessica Kingsley Publishers.

$\mathrm{Xu}$, Y., Filler, J. (2008). Facilitating Family Involvement and Support for Inclusive Education. The School Community Journal. 18 (2). 53-71 